\title{
Research progress on the removal of phthalic acid esters in water
}

\author{
Sheng ZHANG $^{1,2}$, Wei ZHANG ${ }^{1,2}$, and $\operatorname{Li~LIN~}^{1,2^{*}}$ \\ ${ }^{1}$ Basin Water Environmental Research Department, Changjiang River Scientific Research Institute, 430010 Wuhan, China \\ ${ }^{2}$ Key Lab of Basin Water Resource and Eco-Environmental Science in Hubei Province, 430010 Wuhan, China
}

\begin{abstract}
Phthalic acid esters (PAEs), as a kind of persistent organic pollutants, are classified as environmental hormones, and their estrogenic effects can cause great harm to the reproductive system and nervous system of the organism. The environmental pollution and toxicological effects caused by this substance have received global attention, so how to effectively remove PAEs in the environment has become a current research hotspot. This paper summarizes and reviews the common removal methods of phthalates in water, including physical methods, biological methods and chemical methods, and finally prospects for future development.
\end{abstract}

\section{Introduction}

Phthalic acid esters (PAEs) are artificially synthesized organics with large production volume and wide application in the world. They are mainly used as plasticizer in more than 100 products, such as toys, packaging materials and cosmetics to improve the flexibility and processability of polymer materials [1]. They are generally colourless or slightly yellow, odourless, oily viscous liquid, slightly soluble in water and easily soluble in organic solvents. With the growing of the side chains, the fat solubility and boiling point of different phthalates are also higher [2].

As PAEs have low solubility in water and are not chemically bonded to the polymer, they can be easily released from the product and migrate to the environment [3]. At present, PAEs have been detected in various environments, including surface water, groundwater, sediments, atmosphere, aerosol particles and soil, etc., with concentrations ranging from $\mathrm{ng} / \mathrm{L}$ to $\mathrm{mg} / \mathrm{L}$ [4-6]. Recently, with the continuous deepening of research on PAEs, a large number of experiments have shown that the PAEs have carcinogenicity, teratogenicity and mutagenicity. For example, it's harmful to aquatic organisms (fish, algae and invertebrates), vegetables, crops, and can also be passed through the food chain to be enriched in the human body, thereby disrupting human endocrine [7-9]. Some kinds of PAEs have been listed by some international colleagues as priority control pollutants and endocrine disruptors, including Di-n-butyl phthalate (DBP), Di(2-ethylhexyl) phthalate (DEHP), Din-octyl phthalate (DNOP), Diethyl phthalate (DEP), Dimethyl phthalate (DMP), Butyl benzyl phthalate (BBP) [2].

In recent years, with the emphasis on the quality of life, more and more attention be paid to environmental issues. Therefore, it was a hotspot that how to effectively remove
PAEs in the environment. The common removal methods of phthalates in water were summarized and reviewed in this paper, which will be helpful to provide a reference for the optimization of PAEs removal effect in the future.

\section{Removal method of PAEs in water}

\subsection{Physical method}

\subsubsection{Coagulation/flocculation}

Coagulation is a typical water treatment process, which aims to destabilize suspended particles facilitating agglomeration. In general, these particles coalesce to form a floc that can be readily removed by decantation procedures and filtration. Commonly coagulants include $\mathrm{Al}_{2}(\mathrm{SO} 4)_{3}, \mathrm{FeCl}_{3}$ and $\mathrm{FeSO}_{4}$. Zhang [10] investigated the removal of PAEs from landfill leachate through a complexation-flocculation process using ferric chloride, aluminium sulfate and poly aluminium chloride as coagulants. The results revealed that hydrophobic contaminants with $\log \mathrm{K}_{\mathrm{OW}}$ greater than 4 in wastewater can be removed through the complexation-flocculation process. Zheng [11] evaluated the feasibility of removing PAEs from fresh and partially stabilized landfill leachates by a coagulation and flocculation process, the result showed that less than $30 \%$ of PAEs in the fresh leachate could be removed. Asakura [12] used $\mathrm{FeCl}_{3}$ to reprocess the DEHP in the treated leachate under different dosages and $\mathrm{pH}$ conditions, and the removal rate achieved $70 \%$. The above results showed that the removal effect of coagulation/flocculation technology on PAEs is not only related to the $\mathrm{K}_{\text {ow }}$ value of PAEs, but also to the difference in the type of flocculant and reaction conditions.

\footnotetext{
* Corresponding author: linli1229@hotmail.com
} 


\subsubsection{Adsorption}

Adsorption is an effective method to remove organic matter in water. Activated carbon is one of very effective adsorbent due to its large surface area and chemical properties. The effect of activated carbon adsorption was used on the removal of DBP by Adhoum [13], the result showed activated carbon has a good adsorption effect on DBP, and the adsorption capacity of activated carbon can be greatly improved by impregnation of tetrabutylammonium and copper. In addition, it has shown that the solution $\mathrm{pH}$ has an important effect on the adsorption rate as it determines the charge density of the activated carbon [14].Venkata-Mohan [15] studied the adsorption of DEP from aqueous phase by commercial activated carbon, the results demonstrated that adsorption of DEP is highly dependent on the solution $\mathrm{pH}$, when the $\mathrm{pH}$ value increases from 2.0 to 10.5 , the adsorption capacity of DEP decreases. Other adsorbents have also been used to remove PAEs from aqueous solutions, such as chitosan, manganese oxide and clay, etc.

It only transfers PAEs from the water phase to the surface of the adsorbent by coagulation/flocculation and adsorption, without changing the form and properties of pollutants, and the PAEs cannot be completely removed. Moreover, they have some limitations, such as high price, difficult to recycle, short service life and so on.

\subsection{Biodegradation}

Microbial degradation is considered to be one of the main ways to remove PAEs from natural water bodies and wastewater. In water bodies, there are three ways to $t$ degrade organic pollutants by microorganisms [16]: First, organic pollutants are used as the sole carbon source and energy to metabolize and degrade them. Second, the microorganisms cooperate with each other to degrade the organic pollutant substrate, Third, the refractory organic matter, which is a non-growth substrate, is degraded in a co-metabolism manner with the growth substrate.

Wang [17] used DBP as the only carbon in the culture medium studied the results showed that the degradation rate of DBP could be nearly $90 \%$ in 48 hours. Chen [18] isolated and characterized a novel strain, Cupriavidus oxalaticus strain E3, from sediment for PAEs degradation. The transformation of DBP and DEHP as the sole carbon source by strain E3 was systematically studied in the darkness through the kinetic studies and analysis of intermediates. After the initial lag pause of $5 \mathrm{~h}-8 \mathrm{~h}$, the strain efficiently degraded $87.4 \%-94.4 \%$ of DBP and $82.5 \%-85.6 \%$ of DEHP with the initial amount of 200 $\mathrm{mg} / \mathrm{L}$ after $60 \mathrm{~h}$ incubation. There are some other microorganisms, including strains of Achromobacter from sewage sludge [19], Agromyces from soil [20], Bacillus from agricultural soil [21], Curvibacter from river sediment [22].

Nowadays, it has become a popular trend to domesticate and isolate high-efficiency PAEs degrading bacteria from special environments for microbial degradation. However, this method is often limited by some factors, such as temperature, degrading bacteria, and processing techniques. and the degradation process often takes a long time, usually several days or more.

\subsection{Chemical method}

Chemical oxidation is widely concerned due to its fast reaction speed and thorough decomposition. The most notable feature of this treatment method is that hydroxyl radicals are the main oxidant to react with organic substances, and the reaction products are further oxidized and decomposed into $\mathrm{CO}_{2}, \mathrm{H}_{2} \mathrm{O}$ and inorganic acids product, so as to achieve the purpose of oxidative degradation of organic matter. It mainly includes Fenton reaction, ozone oxidation, photocatalysis, etc.

\subsubsection{Fenton reaction}

Fenton reagent mixed by hydrogen peroxide and iron salts, is an oxidant with highly oxidative effect. The primary reactions of representative Fenton process are [23]:

$$
\begin{aligned}
& \mathrm{Fe}^{2+}+\mathrm{H}_{2} \mathrm{O}_{2}+\mathrm{H}^{+} \rightarrow \mathrm{Fe}^{3+}+\cdot \mathrm{OH}+\mathrm{H}_{2} 0 \\
& \mathrm{Fe}^{3+}+\mathrm{H}_{2} \mathrm{O}_{2} \rightarrow \mathrm{Fe}^{2+}+\cdot \mathrm{OOH}+\mathrm{H}^{+}
\end{aligned}
$$

where $\cdot \mathrm{OH}$ is the hydroxyl radical and $\cdot \mathrm{OOH}$ is the superoxide radical.

$\mathrm{He}$ [24] has studied the removal of PAEs from the fresh and mature landfill leachate by Fenton treatment. The result showed that more than $40 \%$ of PAEs were removed from the raw mature leachate while only $20 \%$ of PAEs in the raw fresh leachate were reduced, respectively. When $1.5 \mathrm{mg} / \mathrm{L}$ of PAES was added to fresh and mature leachate, the removal efficiencies of PAEs was above $88 \%$. The results indicated that the removing efficiencies of the PAEs in the leachate had a relationship with their concentrations. Zhang [25] conducted a comprehensive study of the chemical oxidation degradation of DEP through Fenton processes. Effects of various operating parameters that considerably affect DEP decomposition were investigated, including solution $\mathrm{pH}, \mathrm{H}_{2} \mathrm{O}_{2}, \mathrm{Fe}^{2+}$, and DEP concentration. Under the reaction conditions of $\mathrm{pH}$ value of 3.0 , concentration of $0.3 \mathrm{mM}$ of $\mathrm{Fe}^{2+}$, and $6.0 \mathrm{mM}$ of $\mathrm{H}_{2} \mathrm{O}_{2}$, the removal efficiency of DEP achieved $98 \%$ after $170 \mathrm{~min}$.

\subsubsection{Ozone oxidation}

Ozone is an oxidant with strong oxidation ability, which oxidation process is selective. Generally, ozone oxidation is only effective for organic pollutants containing specific functional groups. It has decontamination ability under other auxiliary conditions such as transition metals, activated carbon, and light.

Tatianne [26] studied the DEP removal by a water treatment process based on the coupling of ozone and activated carbon. Compared to the single ozonation process, this coupling was found to enhance DEP degradation kinetics and completely remove pollutants. Ruihuan [27] investigated the catalytic activity of ironloaded SBA-15 (Fe/SBA-15) for ozonation of DMP in aqueous solution. The mineralization of DMP followed an apparent first-order kinetics. The rate constant in Fe/SBA$15 / \mathrm{O}_{3}$ was $0.0058 \mathrm{~min}^{-1}$, which was 3.9 times higher than 
that of $\mathrm{O}_{3}$ alone, 3.4 and 1.9 times higher than those of SBA- $15 / \mathrm{O}_{3}$ and $\mathrm{Fe}_{2} \mathrm{O}_{3} / \mathrm{O}_{3}$ processes, respectively. The iron content, reaction temperature and initial $\mathrm{pH}$ of DMP solution played important roles in $\mathrm{Fe} / \mathrm{SBA}-15 / \mathrm{O}_{3}$ process, while chloride ion exhibited the slight influence. The synergetic effect between $\mathrm{O}_{3}$ and Fe/SBA-15 adsorption illustrated that $\mathrm{Fe} / \mathrm{SBA}-15$ was a promising catalyst for ozonation process. Chen [28] explored the enhanced ozonation of DMP with ultraviolet radiation, it has found that both $\mathrm{O}_{3}$ and $\mathrm{O}_{3} / \mathrm{UV}$ treatments were effective in removing DMP completely, and the removal efficiencies of both chemical oxygen demand and total organic carbons are significantly enhanced by employing the ozonation combined with UV radiation.

\subsubsection{Photocatalytic degradation}

Photocatalytic oxidation is an advanced technology for the elimination of organic pollutants due to its high mineralization efficiency. Among all kinds of photocatalysts, anatase $\mathrm{TiO}_{2}$ has showed excellent UVlight photocatalytic activity, which has been widely studied. Photolysis and photocatalysis of typical PAEs (DMP, DEP, DBP) were carried out in $\mathrm{UV}, \mathrm{UV} / \mathrm{TiO}_{2}$, and $\mathrm{UV}-\mathrm{Vis} / \mathrm{Bi}_{2} \mathrm{WO}_{6}$ systems. The results showed that each system demonstrated different abilities to remove DMP, DEP, and DBP in $300 \mathrm{~min}$ of photolysis and photodegradation reaction. The $\mathrm{UV} / \mathrm{TiO}_{2}$ system showed the strongest degradation ability on selected PAEs, and the removal efficiencies reached 93.03, 92.64, and 92.50\% for DMP, DEP, and DBP in 90 min, respectively [29]. Xu [30] prepared a series of porous polyoxotungstate/titania nanocomposites $\left(\mathrm{PW} 12 / \mathrm{TiO}_{2}\right)$ to the degradation of aqueous phthalate esters (PAEs) including DBP and DEP under the simulated sunlight irradiation. It was found that nearly complete degradation of DEP and DBP was realized after 120 and 90min simulated sunlight irradiation of the PW12/ $\mathrm{TiO}_{2}$ composite with PW12 loading of $19.8 \%$. Similarly, the photoactivity activity of the $\mathrm{PW} 12 / \mathrm{TiO}_{2}$ to DEP and DBP degradation is higher than that of pure $\mathrm{TiO}_{2}$. what's more, the research showed that loading a small amount of $\mathrm{Fe}, \mathrm{Ag}, \mathrm{Cu}, \mathrm{Zn}$ and other heavy metals on $\mathrm{TiO}_{2}$ can also make it have more excellent performance $[31,32]$.

\section{Conclusions and prospects}

The pollution of PAEs in the water environment is becoming more and more serious, which poses a potential threat to human health and the ecological environment, and requires extensive attention from scholars. It is an important direction for future research to find effective methods and technologies to remove these substances. The focus of future research on PAEs removal in water should combine physical, chemical, and biological methods, giving full play to their respective advantages, and studing various combined treatment processes suitable for PAEs degradation, so as to improve the treatment efficiency and reduce the treatment cost.

\section{Acknowledgments}

This study was financially supported by the National Natural Science Foundation of China (No.41907155)

\section{References}

1. Han D, Li J, Cao H, He M, Hu J, Yao S. Theoretical investigation on the mechanisms and kinetics of $\mathrm{OH}-$ initiated photooxidation of dimethyl phthalate (DMP) in atmosphere. Chemosphere 95:50-57 (2014)

2. Daiem M, Rivera-Utrilla J, Ocampo-Perez R, et al. Environmental impact of phthalic acid esters and their removal from water and sediments by different technologies - A review. Journal of Environmental Management, 109:164-178. (2012)

3. Staples CA, Peterson DR, Parkerton TF, Adams WJ. The environmental fate of phthalate esters: a literature review. Chemosphere 35:667-749(1997)

4. Wu, M.H., Liu, N., Xu, G., Ma, J., Tang, L., Wang, L., $\mathrm{Fu}$, H.Y, Kinetics and mechanisms studies on dimethyl phthalate degradation in aqueous solutions by pulse radiolysis and electron beam radiolysis. Radiat. Phys. Chem. 80, 420-425. (2011)

5. Montuori, P., Jover, E., Morgantini, M., Bayona, J.M., Triassi, M., Assessing human exposure to phthalic acid and phthalate esters from mineral water stored in polyethylene terephthalate and glass bottles. Food Addit. Contam. A 25, 511-518. (2008).

6. Ogunfowokan, A.O., Torto, N., Adenuga, A.A., Okoh, E.K., Survey of levels of phthalate ester plasticizers in a sewage lagoon effluent and a receiving stream. Environ. Monit. Assess. 118, 457-480 (2006)

7. David R M, Moore M R, Cifone M A, et al. Chronic peroxisome proliferation and hepatomegaly associated with the hepatocellular tumorigenesis of di (2-ethylhexyl) phthalate and the effects of recovery. Toxicological Sciences, 50(2): 195-205. (1999)

8. Charles A Staples, William J Adams, Thomas F Parkerton, et al. Aquatic toxicity of eighteen phthalate esters. Environmental Toxicology and Chemistry, 16(5): 875-891. (1997)

9. Brown D. R S Thompson. Phthalates and the aquatic environment: Part I. The effect of di-2-ethylhexyl phthalate (DEHP) and di-isodecyl phthalate (DIDP) on the reproduction of Daphnia magna and observations on their bioconcentration. Chemosphere, 11(4): 417-426. (1982)

10. Zhang, C., Wang, Y., Removal of dissolved organic matter and phthalic acid esters from landfill leachate through a complexation flocculation process. Waste Manage. 29, 110-116. (2009)

11. Zheng, Z., Zhang, H., He, P., Shao, L., Chen, Y., Pang, L., Co-removal of phthalic acid esters with dissolved organic matter from landfill leachate by coagulation and flocculation process. Chemosphere 75, 180-186. (2009)

12. Asakura H, Matsuto T. Experimental study of 
behavior of endocrine-disrupting chemicals in leachate treatment process and evaluation of removal efficiency. Waste Management, ,29(6):1852-1859. (2009)

13. Adhoum N, Monser L. Removal of phthalate on modified activated carbon: application to the treatment of industrial wastewater. Separation and PurificationTechnology,38(3):233-239(2004)

14. Radovic, L.R., Moreno-Castilla, C., Rivera-Utrilla, J. Carbon materials as adsorbents in aqueous solutions. Chem. Phys. Carbon 27, 227-405. (2001)

15. Venkata-Mohan, S., Shailaja, S., Rama Krishna, M., Sarma, P.N., Adsorptive removal of phthalate ester (Di-ethyl phthalate) from aqueous phase by activated carbon: a kinetic study. Hazard. Mater. 146, 278-282. (2007)

16. XU HY, ZHOU SL, TAO H, et al. Review of research advancements on degradation of phthalate esters in sewage. University of Shanghai for Science and Technology. 32(05):418-422. (2010)

17. WANG L, LUO QF. Study on biodegraded characteristics of endocrine disruptor di-n-butyl phthalate. JOURNAL OF HYGIENE RESEARCH, (03):187-189. (2003)

18. CHEN FY, LI XL, DONG YQ, et al. Biodegradation of phthalic acid esters (PAEs) by Cupriavidus oxalaticus strain E3 isolated from sediment and characterization of monoester hydrolases. Chemosphere, 266. (2020)

19. Pradeep, S., Josh, M.K.S., Binod, P., Devi, R.S., Balachandran, S., Anderson, R.C. Benjamin, S. Achromobacter denitrificans strain SP1 efficiently remediates di(2-ethylhexyl) phthalate. Ecotoxicol. Environ. Saf. 112, 114-121. (2015)

20. Zhao, H.M., Du, H., Lin, J., Chen, X.B., Li, Y.W., Li, H., Cai, Q.Y., Mo, C.H., Qin, H.M. Wong, M.H., Complete degradation of the endocrine disruptor di(2-ethylhexyl) phthalate by a novel Agromyces sp. MT-O strain and its application to bioremediation of contaminated soil. Sci. Total Environ. 562, 170-178. (2016)

21. Surhio, M.A., Talpur, F.N., Nizamani, S.M., et al. Effective bioremediation of endocrine-disrupting phthalate esters, mediated by Bacillus strains. Water Air Soil Pollut.228 (10), 386. (2017)

22. Ma, D., Hao, Z., Sun, R., et al. Genome sequence of a typical ultramicrobacterium curvibacter sp. strain PAE-UM, capable of phthalate ester degradation. Genome Announc4 (1) :10-15. (2016)

23. Zhao X K, Yang G P, Wang Y J, et al. Photochemical degradation of dimethyl phthalate by Fenton reagent. Journal of Photochemistry \& Photobiology A Chemistry 161(2-3):215-220. (2004),

24. He P J, Zheng Z, Zhang $\mathrm{H}$, et al. PAEs and BPA removal in landfill leachate with Fenton process and its relationship with leachate DOM composition[J]. Science of the Total Environment, 407(17):49284933. (2009)
25. Zhang, Q., Wang, C. \& Lei, Y. Fenton's Oxidation Kinetics, Pathway, and Toxicity Evaluation of Diethyl Phthalate in Aqueous Solution. Journal of Advanced Oxidation Technologies, 19(1), 125-133. (2016).

26. Tatianne Ferreira de Oliveira et al. Use of ozone/activated carbon coupling to remove diethyl phthalate from water: Influence of activated carbon textural and chemical properties. Desalination, 276(1): 359-365. (2011)

27. Ruihuan Huang et al. Catalytic activity of Fe/SBA-15 for ozonation of dimethyl phthalate in aqueous solution. Applied Catalysis B, Environmental, 106(1): 264-271. (2011)

28. Chen Y H, Shang N C, Hsieh D C. Decomposition of dimethyl phthalate in an aqueous solution by ozonation with high silica zeolites and UV radiation. Journal of Hazardous Materials, 157(2-3):260-268. (2008)

29. Wang C, Zeng T, Gu C, et al. Photodegradation Pathways of Typical Phthalic Acid Esters Under UV, UVTiO2, and UV-VisBi2WO6 Systems. Frontiers in Chemistry,7852. (2019)

30. Xu L, Yang X, Guo Y, et al. Simulated sunlight photodegradation of aqueous phthalate esters catalyzed by the polyoxotungstate/titania nanocomposite. Journal of Hazardous Materials, 178(1-3):1070-1077. (2010)

31. Singla P, Pandey O P, Singh K. Study of photocatalytic degradation of environmentally harmful phthalate esters using Ni-doped $\mathrm{TiO} 2$ nanoparticles. International journal of Environmental Science and Technology, 13(3):1-8. (2016)

32. Yuan B L, Li X Z, Graham N, Reaction pathways of dimethyl phthalate degradation in TiO_2-UV-O_2 and $\mathrm{TiO}_{-} 2-\mathrm{UV}-\mathrm{Fe}(\mathrm{VI})$ systems. Chemosphere, 72(2):.197-204. (2008) 